\title{
Brasil e Estados Unidos nas Percepções de Oliveira Lima e Salvador de Mendonça
}

\author{
Américo Alves de Lyra Júnior* \\ americodelyra@uol.com.br
}

\begin{abstract}
Resumo: O artigo trata das percepções de Oliveira Lima e Salvador de Mendonça sobre a inserção do Brasil na América. Lima e Mendonça foram diplomatas e intelectuais que discutiram idéias ressurgidas no Brasil a partir da década de 1870, as quais se mostravam contrárias à prática do trabalho servil e simpáticas à causa republicana. Idéias que também eram comuns a outros intelectuais latinoamericanos porque tinham por "pano de fundo" reflexões acerca da doutrina Monroe e do Corolário Roosevelt. Estudamos essas idéias através de artigos jornalísticos e de obras completas dos autores, observando os discursos correntes nas décadas pesquisadas. Os discursos foram analisados a partir do conceito de geração, de Karl Mannheim, para quem as gerações são agrupamentos humanos que vislumbram a realidade de forma muito comum, pois se desenvolveram em um mesmo processo histórico e social.
\end{abstract}

Palavras-chave: doutrina Monroe, Oliveira Lima, Salvador de Mendonça.

\section{INTRODUÇÃO}

Este artigo representa um esforço no sentido de apresentar concepções correntes na vida intelectual da América Latina no final do século XIX e começo do século XX, a partir do Brasil e mediante as reflexões de dois diplomatas: Oliveira Lima e Salvador de Mendonça. Lima e Mendonça discutiram idéias que eram comuns às pessoas instruídas da região, como temas acerca da "evolução histórica" e do futuro da América não saxônica. Lembramos que essas preocupações retomaram maior acento nos discursos de autores brasileiros em meados da década de 1870, dada à preocupação do Império em conhecer melhor os Estados Unidos, então nação emergente enquanto potência não européia. O Império existia dentro de um contexto distinto do

\footnotetext{
Professor do Departamento de Relações Internacionais da UFR.
} 
estadunidense porque era ainda escravocrata e parcela significativa de seus intelectuais estava seduzida pela idéia de americanizar ou tornar o país uma República. Salientamos que, mesmo com a República proclamada, a inserção brasileira na América continuaria problemática por longo tempo e um novo conjunto de assuntos seria desenvolvido pela inteligência nacional. Com o advento do Brasil República, se pensava também as conseqüências da substituição das administrações militares por governos civis no campo econômico e nas relações internacionais.

Optamos por apresentar esse ambiente através de temas recorrentes em Oliveira Lima e Salvador de Mendonça nas relações da América LatinaBrasil com os Estados Unidos, no final do século XIX e começo do século $\mathrm{XX}$, quando as diferenças entre as duas Américas eram pensadas com mais intensidade por intelectuais latinos, os quais se dividiam entre admiradores do modelo estadunidense e os que o abominavam. Setores das elites brasileira, ${ }^{1}$ de inspiração monarquista ou republicana, se encantavam com o modelo de organização política estadunidense. Os primeiros admiravam o seu apelo à constitucionalidade e os últimos elogiavam seu federalismo. O próprio imperador Pedro II manifestava interesse pela aproximação comercial das duas nações. Salvador de Mendonça, então cônsul brasileiro nos Estados Unidos, empenhou-se para consolidar um tratado comercial já discutido com o presidente norte-americano Grover Cleveland. Contudo, seus esforços foram vencidos pela indisposição de alguns políticos do Império com a respectiva aproximação.

Para lograr o intento de apresentar esse ambiente, observamos uma metodologia, três objetivos e duas hipóteses. A metodologia baseou-se no contato com textos produzidos por Oliveira Lima e Salvador de Mendonça em jornais de época, obras completas e de fontes secundárias de biógrafos, sobretudo de contemporâneos de Lima e Mendonça. A leitura desse material deu-se pela idéia de que seus autores pertenciam a uma mesma geração e seus pré-conceitos eram referenciais comuns para se compreender o mundo. Quanto aos objetivos:

a) Analisar as percepções de Salvador de Mendonça e Oliveira Lima sobre as relações do Brasil com os Estados Unidos observando, por meio dos autores, as idéias de americanização correntes no período;

b) Compreender os discursos sobre América de Oliveira Lima e Salvador de Mendonça confrontando-os com as modificações sofridas pelo monroismo e

c) Procurar as divergências conceituais de Lima e Mendonça sobre as Américas e o Brasil. 
No campo das hipóteses tem-se que:

a) A percepção dos autores acerca dos discursos de americanidade e República indicam os "olhares e sentimentos" de uma geração;

b) Questionar os caminhos que conduziram as re-significações de Oliveira Lima e Salvador de Mendonça sobre América Hispânica-Estados Unidos e a suposta superioridade geral do último.

Assim se analisa o discurso de Oliveira Lima sobre o desenvolvimento da América considerando que, para Lima, as Américas possuíam evolução própria, com convergências então denominadas de particularismos. No caso de Salvador de Mendonça, contemplamos suas considerações sobre as mudanças da política externa dos Estados Unidos para a América Latina no governo Roosevelt.

O PARTICULARISMO AMERICANO: CAUDILHISMO, ESCRAVIDÃO E PACTO FEDERATIVO

Oliveira Lima (s/d, p. 61-62) supunha que o desenvolvimento das Américas, ibéricas e saxônica, guardava particularismos ou instituições contemporâneas e similares. Considerava-se a escravidão como instituição ou particularismo. Ela foi comum a todas as colônias americanas. No Brasil, especialmente, se manteve apesar da centralização do poder através da Monarquia. Antes de se consolidar a centralização, entretanto, destaca-se outro particularismo, pelo menos com maior acento na América do Sul: a corrupção de militares do exército para atender a interesses e paixões individuais que ameaçavam decompor a sociedade porque animava todo tipo de discórdias entre facções rivais, as quais derramavam sangue de nacionais (LimA, 1986, p. 84). Na história brasileira, em particular, esse período correspondeu à Regência.

Outro aspecto que contribuiria com esse particularismo, no Brasil, relaciona-se às diferentes condições econômicas de suas províncias. Estas se dividiam entre as que mais precisavam e as que podiam abandonar a instituição do trabalho servil sem ônus. Destas, Amazônia e Ceará tornaram-se exemplo. Ambas as províncias possuíam poucos escravos e libertá-los era tarefa menos árdua. Pernambuco e São Paulo, entretanto, se aferravam à escravidão em função do número de cativos. Algo parecido com os Estados Unidos, onde o elemento servil também dividiu a nação em terras de trabalhadores livres escravos. As diferenças se davam quanto às formas e condições de solução do problema, que na nação brasileira teriam sido resolvidos por via parlamentar e no interior de um ambiente pacífico. 
Esse particularismo, no Brasil, provocou, como indicado, uma divisão entre províncias. A divisão das províncias com escravos e aquelas livres do trabalho servil também possibilitou um tipo de ordenação da nação brasileira, a qual se deu por meio de localizações distintas quanto ao modelo de trabalho. Para Oliveira Lima, uma das conseqüências desse ordenamento foi a realização da idéia de federalismo. Algo comum a todas as nações da América e não só aos Estados Unidos, então tidos por muitos como o país onde essa idéia e também a sua prática de fato existiram.

Oliveira Lima admitia que o federalismo tivesse entre os norte-americanos seu exemplo triunfante. Mas, no Brasil, o federalismo não significou apenas uma cópia republicana do modelo estadunidense (LimA, s/d, p. 63). Ele possuía uma tradição própria, a qual lhe dava um conteúdo que Lima (1986, p. 85) denominaria de espírito colonial. Este espírito se manifestou nos movimentos nativistas, de forma a dispersar a atenção do povo da idéia de uma grande pátria ou de compreender o país como um todo de língua e tradições comuns. O povo se percebia, como no período colonial, enquanto municipalidades e sentia-se preso ao que o autor denominava de pequena pátria ou região em que havia nascido e se criado.

Os brasileiros, segundo Oliveira Lima, aceitaram e se adaptaram ao federalismo a partir de 1822. Neste ano, se construía o único Império americano que consolidaria a unidade nacional de forma distinta e, de acordo com Lima, superior aos esforços dos vizinhos hispano-americanos. $\mathrm{O}$ autor afirmava, igualmente, que a própria Constituição imperial de 1825 resguardava o federalismo. Este último seria mais perceptível com a Regência quando, através do ato adicional de 1834, descentralizou-se o poder do Estado. Atitude de conseqüências dissolventes para a nação, pois colocaria em risco aquela unidade por meio de revoluções. Entretanto, segundo Oliveira Lima (1986, p. 86), as distorções seriam corrigidas com a situação conservadora de 1841.

Oliveira Lima tentava mostrar que o federalismo no Brasil teve existência anterior à República instalada no ano de 1889. A existência do federalismo tinha uma história com adaptações, conquistas, insucessos e triunfos; ora ele possuiu maior acento e, depois, foi reduzido a proporções menores. Entretanto, nunca desapareceu da vida brasileira. $\mathrm{O}$ federalismo, em toda a América do Sul, seria também uma herança ibérica, posto se relacionar com o transporte de instituições da Península Ibérica para a América Latina que era, a esse tempo, um novo cenário para novos elementos.

A América Latina como um todo comungaria desse particularismo, o qual diferenciava esse continente do europeu. A citada diferença se rela- 
cionava à política de nacionalidades que, no Velho Mundo, favoreceria a prática de grupamento, como se verificava pelos exemplos que iam de Napoleão a Bismarck. No Novo Mundo, Simón Bolívar não logrou reunir porções homogêneas de um mesmo império. Lima (s/d, p. 64) lembrava que Bolívar viu-se obrigado a separar a Audiência de Charcas elevando-a a nação batizada com seu nome. Como contraponto ao discurso de Oliveira Lima, merece registro a opinião de Eric Hobsbawm (2000, p. 126) acerca das nacionalidades na Europa. Hobsbawm não percebe aquela prática de grupamento, antes concebe uma afirmação de nacionalidades rivais em um ambiente onde se procurava o direito de ser um Estado independente. Ocorriam, igualmente, outros fenômenos que poderiam parecer, em um primeiro momento, um simples processo de grupamento como asseverado por Lima. Como lembra Eric Hobsbawm, a Alemanha e a Itália se unificaram sob os reinos da Prússia e da Savóia, respectivamente. A Hungria alcançou um governo doméstico pelo Compromisso de 1867 e o Estado romeno foi resultado da fusão de dois principados danubianos.

Quanto a América Latina, Oliveira Lima entende que Simón Bolívar não conseguiu manter unidas as parcelas homogêneas de um mesmo vicereinado, o de Nova Granada. Após a independência da América espanhola, segundo Malcolm Deas (2004, p. 505), criou-se uma unidade política que reuniu a Audiência de Quito, a capitania-geral da Venezuela e o vice-reino de Nova Granada. Essa unidade, denominada de República da Gran Colombia, foi dissolvida. Lima entende essa dissolução como sendo prova da incapacidade de Bolívar no sentido de preservar Quito unida à Grande Colômbia que, posteriormente, se fragmentaria na Nova Granada e na Venezuela. Oliveira Lima também afirmaria que a citada dissolução manifestava um federalismo em fase de gestação, o qual seria, igualmente, um particularismo americano. Deas tem outra compreensão. Aquela república era um ente transitório que cumpriu sua finalidade antes mesmo da morte de Simón Bolívar, pois as distâncias das províncias para o governo localizado em Bogotá eram enormes e não havia vínculos econômicos fortes dessas províncias entre si. Nos Estados Unidos, igualmente, dava-se guerra cruenta para separar os estados do Norte e do Sul, comprometendo-se a União. Enquanto que, na Europa, se travava guerras para construir unidades como a da Alemanha e da Itália. Bem verdade que o caso alemão era ímpar, posto que o feudalismo germânico ainda existisse quando Oliveira Lima pensava a América.

O gênio de Bolívar assemelhava-se aos anseios dos federalistas norte-americanos. Eles desejavam diluir a autonomia das partes pela autoridade do todo, sobrelevando-se os interesses coletivos sobre os individuais. 
Revela-o a demarcação territorial na América espanhola, a qual se deu através do principio do uti possidetis juris. Esse foi o caso da desavença de limites entre Argentina e Chile, arbitrada pelo rei da Inglaterra. Da contenda entre Argentina e Paraguai, decidida pelo presidente norte-americano Chester Alan Arthur Hayes. Da disputa entre Bolívia e Peru pelos territórios do Acre, adquiridos pelo Brasil, e decidida pelo presidente argentino. Outras como da Colômbia e Venezuela arbitrada pela rainha regente da Espanha.

Outra característica do aludido gênio de Simón Bolívar teria sido a superação do militarismo. Bolívar apelou ao principio regulador entre as nações, o qual residia no arbitramento. $O$ historiador equatoriano Jorge Nuñez (2008, p. 1), na sua biografia sobre Bolívar, comenta que o biografado, no tocante ao gênio, foi também vivaz, tendo decidido a vitória através do seu ímpeto pessoal, na única batalha travada em território do atual Equador; Simón Bolívar teria contribuído, por meio do seu ímpeto, na diplomacia ou na guerra, com a consolidação da independência e das Repúblicas na América hispânica. Dessa forma, os discursos de Jorge Nuñez e de Oliveira Lima enfocam prismas diversos de um mesmo acontecimento e coincidem em reforçar aquela virtude relacionada ao ímpeto.

Simón Bolívar teria tido, ainda, o mérito de retirar as nações hispanoamericanas da esfera estreita do patriotismo, ou bairrismo, para Oliveira Lima, elevando as relações dos países da América espanhola para o nível superior da harmonia internacional e na busca de um projeto de alianças continentais. Contudo, o espírito desse personagem era autocrático e inspirou, no organismo político da América, seu imperialismo disfarçado de unidade de raças (LimA, s/d, p. 65).

Simón Bolívar, assim, antecedia a doutrina Monroe, no tocante à preocupação com a afirmação e a segurança das independências latino-americanas. Estas transformaram as ex-colônias espanholas em Repúblicas ainda frágeis e imbuídas de princípio federativo. Aliás, todas as ex-colônias americanas reconheciam esse princípio que, consoante Lima (s/d, p. 67), representava o traço fundamental da política americana; uma política que tinha suas bases nas metrópoles ibéricas.

A política americana tinha antecedentes na tradição de governo local dessas metrópoles. A Coroa portuguesa, por exemplo, reviveu no Brasil um sistema muito próximo ao feudal. A Coroa distribuiu, na primeira metade do século XVI, vastas capitanias para fidalgos da Corte e personagens de consideração. Ao monarca reservavam-se os direitos suseranos, a saber: aplicação suprema da justiça e a cobrança de certos tributos (LiMA, s/d, p. 69-70).

História Revista, Goiânia, v. 13, n. 2, p. 315-330, jul./dez. 2008 
Houve um esboço de centralização no Brasil quando da união das Coroas espanhola e portuguesa. Uma centralização ilusória (LiMA, s/d, p. 70). A Espanha até se afeiçoava a essa prática, pois retirou as atribuições judiciárias dos chefes locais ou governadores da colônia portuguesa na América. A partir de 1580, inclusive, quase não existiam mais donatários. Entretanto, a reintegração da autoridade portuguesa e sua posterior recuperação dos domínios americanos reorientaram a organização brasileira.

As capitanias retornaram à condição de unidades administrativas sujeitas diretamente à metrópole. Cada unidade administrativa tinha vida própria e se tornava mais independente de suas vizinhas. Esta prática foi recorrente em Portugal, onde a divisão administrativa citada unificou a nação:

[...] Suas provincias eram meras divisões administrativas, apenas differenciadas no pittoresco dos trajes regionais. Este resultado seguirase logo á conquista do paiz aos mouros e á sobreposição da realeza, apoiada nas communas, á nobreza territorial que noutras terras tanto embaraçou a obra da unificação nacional. (LıMA, s/d, p. 71)

A unificação espanhola ocorreu mediante processos distintos da portuguesa. Lima (s/d, p. 72) afirmava que essa unidade consolidou-se pelo enlace entre as dinastias de Aragão e Castela, que integrou territorialmente a Espanha de forma precária e tardia. As instituições mantiveram-se peculiares e observavam-se nos habitantes diferenças de caráter e civilização.

Os espanhóis, pela sua tradição, transplantaram para a América um sistema de esferas de governo. Suas possessões tinham vice-reinados, com capitanias gravitando ao seu redor. Tentou-se a mesma experiência no Brasil, quando da união ibérica. Dividiu-se a América portuguesa em dois e até três estados, tendência centralizadora que ia de encontro com as intenções de Lisboa.

Para Lima (s/d, p. 74-75), as tradições ibéricas transplantadas para o novo mundo deram à América hispano-portuguesa uma missão conspícua na história da humanidade. Neste sentido, a Espanha foi mais conseqüente:

[...] com a sua orientação constitucional do que Portugal, porquanto, ao mesmo tempo que recortava o seu immenso imperio colonial em diversos grupos administrativos separados e isolados, deixava cultivar-se com maior carinho a semente das franquias municipaes, as quaes eram occasionalmente tomadas de assalto nas possessões portuguezas, particularmente no Brazil. 
Essa missão conspícua pertencia às Américas espanhola, inglesa e portuguesa, que representavam a união federativa. Nos Estados Unidos, a missão dessa união foi obra dos primeiros homens de Estado. A partir da cidade de Caracas, ela foi proposta a outras cidades colombianas e proclamou-se autonomia municipal em 1810, um ano antes da independência da Venezuela.

Indicava-se, assim, a união federativa como meio de obstar a política expansionista de Napoleão, no sentido de criar uma grande confederação americana. A solução foi reiterada, em 1809, pelos cabildos de Buenos Aires e Caracas. Ressalta-se, igualmente, que a aplicação daquela política na Península Ibérica foi o ponto de partida da organização das nacionalidades neo-espanholas na América (LimA, s/d, p. 76).

Contudo, o último vestígio do sistema espanhol de agrupamento sistematizou-se com o projeto do conde de Aranda. O conde previa que Cuba, Porto Rico e uma posição da América do Sul, a ser determinada, dependeriam imediatamente da Coroa espanhola. Do restante das Índias Ocidentais resultariam grandes reinos, como Nova Espanha - México, Peru e Terra Firme - Nova Granada.

No tocante aos Estados Unidos independentes, Oliveira Lima (s/d, p. 78) afirma sua reticência para com os agitadores pró-independência na América Latina. Jefferson, ministro na França em 1787, desanimou o brasileiro Maia. Este pedia apoio para a libertação do Brasil.

Monroe, Secretário de Estado em 1812, defendia a neutralidade na contenda hispano-americana, na qual Napoleão tomava parte. Ainda assim, os Estados Unidos serviram de exemplo para as novas nacionalidades que se formavam na América. A predileção pelo modelo estadunidense ocorria pelo fato de ser, à época, o único exemplo de governo autônomo da América considerado aceitável, segundo Oliveira Lima. Existia outro exemplo de autonomia, o do Haiti. Este, contudo, era tido, pelas elites que conduziam as independências hispano-americanas, como a pior alternativa $\mathrm{e}$ deveria ser evitado a todo custo. Dessa forma, era natural que os demais países pretendessem imitar os norte-americanos. Contudo, existiam, também, aqueles que preferiam a monarquia.

Lima (s/d, p. 80) revelava que os congressistas de Tucumàn e revolucionários de Buenos Aires compreendiam, porém, ser:

[...] a solução monarchica a mais adequada para livrar o seu paiz da indisciplina das paixões e dos horrores da guerra civil. Se um Infante da Hespanha, se a propria dona Carlota Joaquina, irmã mais velha de Fernando

História Revista, Goiânia, v. 13, n. 2, p. 315-330, jul./dez. 2008 
VII, casada com o Principe Regente de Portugal e então residente no Rio de Janeiro, tivesse desembarcado no Prata, era certa sua acclamação delirante.

Até a Venezuela, importante foco hispano-americano de irradiação do sentimento de independência, se ressentia de não ter uma cabeça para coroar, segundo Lima. Nesse ambiente, a Inglaterra estabeleceu uma espécie de doutrina Monroe para a América do Sul. O governo britânico também mediou as relações entre Brasil e Portugal.

Mas o reverso também era verdadeiro. A América do Sul representou suporte para a Inglaterra. A Europa fora pacificada com a derrota de Napoleão e a Santa Aliança criou sentimentos de antipatia ao liberalismo britânico, de modo que os ingleses necessitavam de novos lugares para desenvolver sua economia em crescente expansão.

Por fim, lembramos que a ausência de apoio dos Estados Unidos na América do Sul corroborou para a hegemonia britânica, pois a emancipação sul-americana se consumou sem auxilio estadunidense. Compreendese, desse modo, a contribuição da Grã-Bretanha às novas nações, nos campos diplomáticos e financeiros. Hegemonia que foi contestada pelos estadunidenses ao longo do século XIX e nas primeiras décadas do século $\mathrm{XX}$, por meio da doutrina Monroe, a qual sofreu alterações de conteúdo e de prática até lograr o denominado Corolário Roosevelt.

\section{América e Corolário Roosevelt: percepções de Salvador de Mendonça}

Oliveira Lima e Salvador de Mendonça não concordavam com a orientação dada pelo barão do Rio Branco à política externa brasileira, em relação aos Estados Unidos e à América do Sul. As discordâncias de Lima e Mendonça, quanto à orientação do barão, se fundamentavam nas mudanças de sentido da doutrina Monroe. Desses sentidos eles temiam, sobretudo, o corolário Roosevelt.

Os dois brasileiros entendiam que a aproximação com os Estados Unidos, sendo este uma potência mundial não européia, implicava riscos significativos à soberania brasileira e à das demais nações americanas. Salvador de Mendonça revelava essa preocupação desde 1890, por meio da aprovação do arbitramento obrigatório, quando cogitava dos perigos para o continente americano em deixar os Estados Unidos sem amarras jurídicas. Estas o impediriam de, enquanto nação hegemônica na América, submeter os demais países aos seus interesses. Para Mendonça, o momento 
apropriado seria o da Primeira Conferência Americana, porque o gigante não possuía, ainda, noção exata da sua força.

Oliveira Lima também discorria no sentido perigoso de se deixar os Estados Unidos livres para defender seus interesses. Lima argumentava que a anuência da diplomacia brasileira ao pan-americanismo do norte contribuía para tornar o continente alvo fácil para os interesses norte-americanos. Neste caso, cabe a observação de uma preocupação de consolidação de laços com a Europa, tema quase ausente nas representações de Salvador de Mendonça, então preocupado com a política externa de Roosevelt para a América Latina. Mendonça e Lima reprovavam o caráter de protetorado dessa política, a qual entendiam ofensiva à dignidade e à soberania das demais nações do continente. Além do que Salvador de Mendonça compreendia que as relações estadunidenses com o Brasil sempre foram amigáveis, com poucos atropelos.

No caso do México, os Estados Unidos fortaleceram seu prestígio internacional a partir da ação contra o Império instaurado ali pelos europeus, mesmo depois de décadas após a independência. Desta ação em diante, os estadunidenses foram procurados por nações latino-americanas e a doutrina Monroe reclamada por outros tantos países do continente, que reclamariam a doutrina, no sentido de se protegerem das ameaças de potências européias, as quais consideravam possibilidades de estender seu poder até a América do Sul.

Para Salvador de Mendonça, esse prestígio foi usado por Grover Cleveland em seu primeiro mandato, quando do episódio que envolveu a Inglaterra e a Venezuela em questões limítrofes. Cleveland obteve êxito, pois os ingleses cederam à exigência estadunidense de arbitramento. MacKinley sentiu esse prestígio, na qualidade de uma opinião pública inflamada, que levou os Estados Unidos a combaterem a Espanha. Neste caso, existiam os defensores do fim da intervenção hispânica em Cuba e os desejosos de expansão dos territórios norte-americanos, destacando-se, nesse grupo, Roosevelt.

Roosevelt substituiu MacKinley na Casa Branca e orquestrou o expansionismo dos Estados Unidos. Salvador de Mendonça acusava essa iniciativa, por exemplo, de ferir a integridade e soberania da Colômbia, no momento da conquista do istmo para a abertura do Canal do Panamá. A política expansionista estadunidense previa a influência em toda região que ficasse aquém dos limites físicos e da influência dos Estados Unidos. Para Salvador de Mendonça, não seria precipitado imaginar que, por exemplo, as áreas do norte da Amazônia se tornariam protetorado norte-americano, 
como também o mar das Caraíbas e o golfo do México. Neste caso, um mar com a presença européia das Antilhas.

Entretanto, a política de expansão dos Estados Unidos provocou reações na América do Sul. Estados sul-americanos pediram proteção aos estadunidenses, ao longo da segunda metade do século XIX. A Nicarágua assinou tratado de protetorado em 1857, o qual o Senado norte-americano se recusou a ratificar. Haiti e Santo Domingo ofereceram arrendamento ou cessão de sua base naval, os quais também foram recusados (SмITH, 2001, p. 613).

Os Estados Unidos mediavam conflitos de Estados sul-americanos entre si e com as nações européias, que cobravam dívidas desses estados. No primeiro caso, Salvador de Mendonça (1913, p. 227) enfatiza que, no começo da segunda administração Cleveland, o México pretendia solucionar questões de limites com a República da Guatemala. O ministro das Relações Exteriores do México, Mariscal, ordenou que Matias Romero investigasse a reação dos Estados Unidos, no caso de uma intervenção do seu país na República da Guatemala. Romero, então ministro mexicano em Washington, procurou o governo estadunidense para obter a informação reclamada.

Matias Romero comunicou ao secretário de Estado norte-americano, Gresham, que o governo mexicano pretendia solucionar problemas de limites com a República da Guatemala, sem o recurso da força. O secretário, após audiência com o presidente dos Estados Unidos, noticiou que seu país não interviria na questão, mantendo-se neutro.

Salvador de Mendonça (1913, p. 227) pontua que, após a decisão norte-americana com respeito à sorte da República da Guatemala, foi procurado por Lazo Arriaga, ministro da Guatemala em Washington, que mostrou o telegrama de Leon, o ministro das Relações Exteriores dessa República. O telegrama informava que considerável força militar mexicana marchava para a República da Guatemala, com o intuito de invadir seu território. A intenção era de se apoderar da Guatemala, antes mesmo da demarcação de fronteiras. Lazo Arriaga solicitava a ajuda do brasileiro para sensibilizar o secretário de Estado norte-americano e impedir a ação de Matias Romero.

Salvador de Mendonça (1913, p. 228-229) atendeu ao pedido de Lazo Arriaga e procurou o secretário de Estado Gresham. Mendonça mostrou o telegrama a Gresham, que o leu em seguida. Após a leitura, o estadunidense questionou sobre a responsabilidade do seu país com o caso discutido. $\mathrm{O}$ brasileiro informou que os norte-americanos tinham responsabilidade com a premente intervenção mexicana, pois ficara a cargo de um seu patriota a comissão de delimitação de fronteiras entre os países litigiosos. 
Salvador de Mendonça aludia ao tratado de 1821. Na ocasião, um comissário norte-americano presidira a comissão de delimitação de fronteiras. Na época, a Guatemala apresentara um comissário e o México não indicou representante. Passaram-se mais de dez anos e o último país não se movimentara no sentido de suprir a lacuna. Mendonça defendia a idéia de que existiam razões suficientes para os Estados Unidos chamarem os mexicanos à ordem e advogava que os estadunidenses deveriam dar outro curso à questão, resolvendo-a pacificamente.

Para lograr este intuito, bastava reunir a comissão técnica. Salvador de Mendonça (1913, p. 229) lembra que: "O sr. Gresham interveio. Cortou a marcha das forças mexicanas para a fronteira e evitou mais uma guerra injusta. Matias Romero foi revogado por ter deixado vencer-se pelo sr. Lazo Arriaga e viu-se por algum tempo arredado de Washington".

A República da Nicarágua não contou com a mesma sorte da Guatemala. O governo inglês ameaçou essa República com o desembarque de forças para ocupar a alfândega de Corinto. Os ingleses cobravam uma quantia da Nicarágua, a qual apelou para os Estados Unidos, sugerindo a doutrina Monroe. Salvador de Mendonça afirma ter sido procurado, na sua casa, pelo secretário de Estado Gresham. O secretário pedia sua opinião sobre o auxílio dos Estados Unidos à República da Nicarágua. Mendonça mostrou-se contrário aos norte-americanos intervirem na questão, por entender que os estadunidenses não eram aliados dos nicaragüenses e, portanto, não se justificava qualquer intervenção. Como lembra o brasileiro: "[...] E o gabinete de Washington assim resolveu o incidente. Os inglezes cobraram a sua divida e retiraram-se de Corinto" (MendonçA, 1913, p. 230).

Apesar da arrogância do discurso, Salvador de Mendonça revela uma aceitação de consórcio entre as nações americanas. Ele entendia que os países eram livres para agir e buscar estratégias no sentido de proteger suas soberanias. A liberdade se fortalecia e limitava-se pelas alianças assumidas. Elas criavam compromissos entre nações, como o ocorrido com a República da Guatemala. Esta República respeitou deliberações oriundas do tratado de 1821, inclusive, indicando comissário para a comissão de fronteiras, presidida por representante estadunidense.

No momento em que a Guatemala viu-se na iminência de uma invasão mexicana, apelou aos Estados Unidos que, por sua vez, tinha responsabilidade com esse país, dado aquele tratado. A República da Nicarágua, conseqüentemente, não mantinha alianças definidas ou, como se expressou Salvador de Mendonça, não era aliada dos Estados Unidos. 
Salvador de Mendonça (1913, p. 231-232) supunha que, por meio dessa exigência de alianças, os estadunidenses também seriam cerceados no seu desejo de expansão, porque estavam sujeitos a agir pelo mesmo propósito das demais nações americanas. Os norte-americanos não poderiam, portanto, intervir em outra nação por decisão própria e unilateral. Mendonça fornece outros exemplos a esse propósito; o primeiro relativo a Richard Olney, que assumiu a Secretaria de Estado com a morte de Gresham e consultou Mendonça sobre a possibilidade de o Brasil fazer causa comum com os Estados Unidos junto à Inglaterra. Desejava-se forçar os ingleses a se submeterem ao arbitramento, diante da sua questão de fronteira com a Venezuela.

Salvador de Mendonça cogitava que a iniciativa não conviria ao Brasil já que este também disputava uma questão de limites com a Inglaterra. Ainda assim, telegrafou para o Rio de Janeiro para saber a posição do governo brasileiro. A resposta do governo não tardou e confirmou as considerações de seu representante na capital dos Estados Unidos. Meses depois daquele convite, o senador Cushman Davis apresentou projeto de extensão da doutrina Monroe. O projeto não era consensual. Homens públicos, como John Sherman e Richard Olney, temiam problemas para os Estados Unidos, em decorrência dos exageros da doutrina.

Com ou sem os exageros da doutrina Monroe, para o bem ou para o mal, os Estados Unidos afirmaram sua condição de potência na América. Essa asserção corroborava para o temor de Salvador de Mendonça. Os estadunidenses descobriram sua força e intervinham na América do Sul, de acordo com seus interesses e propósitos. A nação norte-americana estabelecia uma nova relação de domínio com os sul-americanos, então subservientes aos seus desígnios, porque se estabeleceu o que tanto se temia: o protetorado dos Estados Unidos.

\section{CONSIDERAÇÕES FINAIS}

Lima e Mendonça analisam temas comuns sobre a inserção brasileira na América, traçando relação entre as demais nações sul-americanas e os Estados Unidos. Lima e Mendonça assumem que a América do Sul teve "uma evolução política" no começo do século XIX, com a região tornandose palco de contestações favoráveis a governos autônomos e próprios, ou acolhendo a Corte portuguesa que fugia de Napoleão. A Corte portuguesa fundou uma administração local ultramarina, que se tornou capital de uma dilatada Monarquia no momento da emancipação política. A América his- 
pânica sofreria com a violência ao longo de sua emancipação porque havia pouca harmonia entre as pessoas que viveriam sob o signo de uma mesma nação.

Assim, Lima e Mendonça percebiam um desenvolvimento desigual entre as Américas, sobretudo as ibéricas e a inglesa. No entanto, apesar das desigualdades, essas Américas teriam particularidades, de acordo com o primeiro autor. Ele as percebia pela idéia de federação. As Américas teriam elementos em comum que se sustentaram ao longo do seu desenvolvimento: os particularismos, que se compuseram como instituições contemporâneas e similares às nações do continente. A escravidão, por exemplo, foi conhecida e praticada em todas as colônias americanas. O federalismo, enquanto idéia, perdurou e foi constantemente ressignificada. No Brasil e nos Estados Unidos, essa idéia quando relacionada ao trabalho provocou uma divisão entre regiões, conforme fossem adeptas ou não do trabalho servil. Divisão que permitira modelar a idéia de federalismo, então comum a todo o continente americano.

Vale salientar que os dois autores pertencem a uma mesma geração que pretendeu "mudar os rumos" do Brasil, conduzindo-o em direção à América. Eles entendiam que, a exemplo de outros membros dessa geração, a República possibilitaria esse novo direcionamento. Tinham, diante de si, o agigantamento dos Estados Unidos, o qual se fortalecia como potência internacional não européia e, ainda, estavam impressionados por "idéias da moda" como as concepções de raça. Oliveira Lima e Salvador de Mendonça julgavam e sentiam por meio desses referenciais que, após a Primeira Guerra, ainda se estendendo à década de 1920, essas concepções estavam repletas de sentido para homens e mulheres que construíam e eram construídos através da história. Lima e Mendonça discordavam em diversos temas, em aspectos particulares, pois eram personalidades distintas, mas se reconheciam através dos discursos que manifestavam alegrias, invejas, medos e práticas de uma geração que buscou, sem êxito pleno, um tipo de inserção internacional do Brasil.

Brazil and United States in Perceptions of Oliveira Lima and Salvador de Mendonca

Aвstract: The article deals with the perceptions of Oliveira Lima and Salvador de Mendonça about the insertion of Brazil in America. Lima and Mendonça were diplomats and intellectuals who discussed the ideas resurged in Brazil from the 1870's decade, which disposed opposition to the practice of the servile work and favorable to the republican objectives. Such ideas were also common to other latin american intellectuals who had as "background" reflections about Monroe's doctrine 
as well as Corollary Roosevelt. We have studied these ideas through journalistic articles and from complete author's works, observing the current discourses in the researched decades. The discussions were analyzed from the concept of generation, by Karl Mannheim, for whom the generations are human groups that glimpse the reality in a common way, because they were developed in the same historical and social process.

KeY wORDS: Monroe's doctrine, Oliveira Lima, Salvador de Mendonça.

NotAs

1 Alan Zuckerman ( $\mathrm{s} / \mathrm{d}$ ) afirma que existe um consenso sobre a tese da assimetria do poder político nas sociedades. Entende-se, assim, que os membros de uma sociedade não compartilham de igual forma do poder. Zuckerman lembra, entrementes, das dificuldades no sentido de se conceituar os grupos que, nessa divisão de poder, se constituem no papel de mandatários. As dificuldades se dão quando da necessidade de localizar os referentes empíricos do conceito, ou, dito de outra forma, no momento de se responder quais os personagens de uma análise e/ou narrativa histórica representam uma elite. Para precisar o conceito, Alan Zuckerman sugere, com base em Gaetano Mosca e Vilfredo Pareto, que uma elite seja identificada dentro de um quadro teórico desde que respeitados os problemas específicos de uma dada pesquisa. Esta postura foi adotada para se tratar do termo elites no artigo. Compreende-se que houve, no Brasil, consoante José Murilo de Carvalho, uma unificação ideológica no Império e na República. A pedra angular, para a formação das elites brasileiras, no sentido de sua unificação ideológica, foi a educação superior. Ela permitiu aos grupos mandatários condições de ascensão dos seus membros na esfera do Estado imperial e republicano. Por isso, nomes que representaram o regime decaído participaram, igualmente, do novo que ascendia. Ou, ainda, justifica Salvador de Mendonça, um militante republicano ter assumido cargos de relevo na Monarquia e Joaquim Nabuco, um monarquista constitucional, ter seu trabalho reconhecido na República. Eles, salvo as diferenças, formavam uma elite com a educação superior, no sentido citado acima.

\section{REFERÊNCIAS}

Carvalho, J. M. A formação das almas: o imaginário da República no Brasil. São Paulo: Cia. das Letras, 1990.

Carvalho, J. M. A construção da ordem: a elite política imperial; Teatro das sombras: a política imperial. 2. ed. Rio de Janeiro: Editora UFRJ/Relume-Dumará, 1996.

Américo Alves de Lyra Júnior. Brasil e Estados Unidos nas Percepções... 
DeAs, Malcolm. A Venezuela, a Colômbia e o Equador: o primeiro meio século de independência. In: Bethell, L. (Org.). História da América Latina: da independência até 1870. Brasília/São Paulo: Fundação Alexandre de Gusmão/Editora Universidade de São Paulo/Imprensa Oficial do Estado, 2004. V. III. p. 505-539.

Hobsbawm, E. J. A era do capital (1848-1875). Rio de Janeiro: Paz e Terra, 2000.

Hobsbawm, E. J. A era dos impérios (1875-1914). 9. ed. Rio de Janeiro: Paz e Terra, 2005.

Lima, O. Nos Estados Unidos: impressões políticas e sociais. Leipzig: F. A. Brockhaus, 1899.

Lima, O. Memórias: estas minhas reminiscências... Rio de Janeiro: José Olympio, 1937.

Lima, O. América Latina e América Inglesa: a evolução brasileira comparada com a hispano-americana e com a anglo-americana. Paris/Rio de Janeiro: Garnier, s/d.

Lima, O. Historia Diplomatica do Brasil: o reconhecimento do imperio. Paris/Rio de Janeiro: Garnier, s/d.

Lima, O. O Império brasileiro (1822-1889). Brasília: Ed. da UnB, 1986. (Coleção Temas Brasileiros, 58).

Lima, O. Pan-americanismo (Monroe, Bolívar, Roosevelt). Brasília/Rio de Janeiro: Senado Federal/Fundação casa de Rui Barbosa, 1980.

Lyra Junior, A. A. Brasil e Estados Unidos nas representações de Oliveira Lima e Salvador de Mendonça (1870-1914): idéias sobre a inserção brasileira na América. Brasília, 2008. Tese (Doutorado em História) - Programa de Pós-Graduação em História, Universidade de Brasília, 2008.

Mendonça, S. de. Situação internacional do Brasil. Rio de Janeiro: Garnier, 1913.

NuñeZ, J. Um hombre llamado Simon Bolivar. Disponível em: <http:// www.edufuturo.com/imageBDE/EF/6929.SimonBolivar.pdf $>$. Acesso em: 2 fev. 2008.

Smith, R. F. Os Estados Unidos e a América Latina, 1830-1930. In: Bethell, L. (Org.). História da América Latina,: de 1870 a 1930. Brasília/São Paulo: Fundação Alexandre de Gusmão/Editora Universidade de São Paulo/Imprensa Oficial do Estado, 2001. V. IV. p. 609-649.

Zuckerman, A. Elite política: lições de Mosca e Pareto. Brasília: Textos de Aula Centro de Documentação Política e Relações Internacionais, s/d. 